\title{
Comparative leaf anatomy of some species of Abies and Picea (Pinaceae)
}

\author{
Balkrishna Ghimire ${ }^{1,2}$, Chunghee Lee ${ }^{3}$, Jongcheol Yang ${ }^{3}$ and Kweon $\mathrm{Heo}^{1 \star}$
}

Received: November 21, 2014. Accepted: March 27, 2015

\begin{abstract}
A number of conifer species are still lacking anatomical data, which is significant because morphological and anatomical data are essential for systematic study. Leaf anatomy was studied in selected species of Abies and Picea using light and scanning electron microscopy. Both genera were found to have typical coniferous and highly xerophytic leaves with sunken stomata and an epidermis covered by a thick cuticle. In the genus Abies, species can be differentiated by the nature of the lignified hypodermis and the number and position of resin ducts. Abies firma and A. holophylla have a continuous hypodermis whereas in A. koreana and A. nephrolepis the hypodermis is discontinuous and represented by isolated cells or groups of four or five cells. On the other hand, in Picea leaf shape, stomata arrangement, and number, position, and nature of resin ducts are the key features for species differentiation. Picea jezoensis has a flattened leaf with stomata distributed on the adaxial surface whereas P. abies and P. koraiensis have a rectangular leaf with stomata found on surfaces.
\end{abstract}

Keywords: Abies, leaf anatomy, Picea, scanning electron microscopy, taxonomy

\section{Introduction}

The Pinaceae comprise a total of 225 species in 11 commonly accepted genera (Abies, Cathaya, Cedrus, Keteleeria, Nothotsuga, Picea, Pinus, Pseudolarix, Pseudotsuga and Tsuga) distributed throughout the world (Farjon 2001). Hart (1987) divided the family into two groups: the presence of resin canals in the seeds and cleavage polyembryony supported the monophyly of Abies, Cedrus, Keteleeria, Pseudolarix and Tsuga and the presence of resin canals in the secondary xylem and leaves having an endodermis with thickened Casparian strips supported the monophyly of Cathaya, Larix, Picea, Pinus and Pseudotsuga. On the other hand, on the basis of the morphological structure of vegetative and reproductive organs, Frankis (1988) distinguished four subfamilies of Pinaceae in a widely accepted classification (Farjon 1990): Pinoideae (Pinus), Piceoideae (Picea), Laricoideae (Cathaya, Larix and Pseudotsuga), and Abietoideae (Abies, Cedrus, Keteleeria, Nothotsuga, Pseudolarix and Tsuga). We considered two genera, Abies and Picea, in a study of leaf anatomy. Both genera show dissimilar morphological features and thus are generally classified in separate subfamilies in most Pinaceae classifications (Hart 1987; Frankis 1988; Farjon 1990; 2001).
Abies, with 49 species, is the second largest genus in the family Pinaceae after Pinus and the largest genus in the subfamily Abietoideae (Farjon 2010). They are naturally found in temperate and boreal regions of the northern hemisphere, chiefly in mountainous regions in North America, Central America, Europe, North Africa, and Asia. The genus has most recently been revised by Liu (1971) and Rushforth (1987) and a full review of previous classification schemes was provided by Farjon and Rushforth (1989). Farjon (2010) categorized the 49 species of Abies into 10 sections and nine subsections. In contrast, the genus Picea, which includes 28-56 species depending on the system of classification used (Farjon 1990; Ledig et al. 2004), is most closely related to the genus Pinus. Farjon (2001) recognized 34 spruce species in his conifer checklist, of which 24 are native to Asia, eight to North America, and two to Europe. It is a very uniform genus and thus difficult to work with from a taxonomic perspective due to species having a relatively narrow range of morphological features and ecological preferences (Wright 1955; Taylor and Patterson 1980; Rehfeldt 1994).

Abies and Picea are associated with each other on the basis of some morphological features like spirally arranged leaves, the absence of short shoots, and a similar form of petiole pulvinus. On the basis of these features Picea was grouped into subfamily Abietoideae along with Abies,

\footnotetext{
${ }^{1}$ Department of Applied Plant Science, Kangwon National University, Chuncheon 200-701, Korea

${ }^{2}$ Division of Plant Conservation, Korea National Arboretum, Pocheon 487-829, Korea

${ }^{3}$ Korea National Arboretum, Pocheon 487-829, Korea

*Corresponding author: laurus@kangwon.ac.kr
} 
Cathaya, Keteleeria, Pseudotsuga and Tsuga by Pilger (1926) and Melchior \& Werdermann (1954); this was later rejected on the basis that a classification based on shoot dimorphism is highly artificial because short shoots are a weak phylogenetic character (Hart 1987; Price 1989). The objective of this study was a systematic comparison of leaf anatomical and surface features of some selected species of Abies and Picea, followed by a discussion of the relationship between these genera on this basis.

\section{Material and methods}

Altogether 18 plant samples were considered for the study, comprising four species of Abies Mill. and three species of Picea A. Dietr (Tab. 1). The collected leaf materials were fixed in FAA (formalin: glacial acetic acid: 50\% ethanol, 5:5:90, by vol.) before being stored in 50\% ethanol. Mature, healthy leaves were selected, cut into small pieces of about 5-6 mm, and dehydrated using an ethanol series. Fully dehydrated leaf materials were passed through a mixture made with alcohol/Technovit 7100 resin combinations (3:1, 1:1, 1:3) and 100\% Technovit and then embedded in Technovit resin 7100 (Technovit, Germany). Serial sections of $4-5 \mu \mathrm{m}$ thickness were cut using disposable knives, stuck onto slide glass, and dried on an electric slide warmer for 12 hours. Dried slides were stained with $0.1 \%$ Toludine blue O (C.I. 52040) for 60-90 seconds, rinsed with running water, and again dried by electric slide warmer for more than 6 hours to remove water. The stained slides were then mounted with Entellan (Merck Co., Germany) and observed under a BX-50 light microscope (Olympus Co., Japan). Photographs were taken with a digital camera system attached to the microscope and multiple image alignment was done with Photoshop CS6 for Windows 2007.

For scanning electron microscopy, mature leaves were cut into small pieces and dehydrated by ethanol series, samples were dried using a Hitachi II critical point dryer (Hitachi Co., Japan) and coated with platinum using an E-1010 ion-sputter (Hitachi Co., Japan). Micrographs were taken under $15 \mathrm{kV}$ using an S-3500N scanning electron microscope (Hitachi Co., Japan).

\section{Results}

\section{Leaf surface}

Leaf surface and stomatal features are quite similar in both genera. In all species studied the stomata are highly sunken and develop in longitudinal rows forming the stomatal bands (Figs.1A-H;2A-F). In Abies species the stomata are found only on the abaxial leaf surface, arranged in two bands (Fig.1A, C, E, G) and in Picea species the distribution of stomata varies according to the leaf shape. Picea abies and P. koraiensis, with rectangular leaves, have only one stomatal band on all four sides (Fig. 2A-B, E-F) and P. jezoensis, which has flattened bifacial leaves, stomata are found only on the adaxial surface and arranged into two bands (Fig. 2C-D) except at the tip of the needle (not shown).

In all species marginal cells, including subsidiary and accessory cells, are papillose (Figs.1B, D, F, H; 2B, D, F). Two sunken elongated guard cells are surrounded externally by four subsidiary cells. Two lateral and two polar subsidiary cells are poorly differentiated externally, which might be due to the presence of a thick cuticle layer. In Picea species, the marginal walls of epidermal cells have numerous small infoldings and that project into the cavities of the cells (Fig. 2B, D, F).

\section{Anatomical features}

\section{Abies firma and Abies holophylla}

These two species belong to section Momi. Within section Momi, A. firma represents the subsection Firmae and A. holophylla represents Holophyllae. Both species leaf cross section clearly reveals a bifacial structure (Fig. 3A-D). The epidermis is single-layered and composed of small elongated or oval-shaped, highly lignified cells (Fig. 3E-F). Numerous stomata are observed on the abaxial leaf surface (Fig. 3G-H). The hypodermis is single-layered with oval-shaped lignified cells (Fig. 3E-G), which is a continuous layer except in the stomatal region of the abaxial surface. Only in a few places particularly in the margin and mid-vein region, the hypodermis comprise more than one cell layer. The mesophyll is composed of parenchyma cells, differentiated into two regions: palisade and spongy (Fig. 3G). The palisade parenchyma is more developed on the adaxial side and consists of radially elongated cells in two or three layers. The spongy parenchyma is organized with loosely arranged polygonal cells, in about $70-80 \%$ of the mesophyll (Fig. 3G). Resin ducts pass through the mesophyll, and some of them are attached to the abaxial epidermis or hypodermis (Fig. 3A-F). The Korean samples of $A$. firma had four resin ducts, two large ones in the mesophyll and two small ones attached to the lower epidermis, (Fig. 3A) while the Japanese sample had only two ducts, both attached to the epidermis (Fig. 3B). In contrast, all three samples of $A$. holophylla had two resin ducts, either attached to the epidermis in the Japanese sample (Fig. 3C) or located in the mesophyll in the Korean samples (Fig. 3D).

The leaves have two collateral vascular bundles surrounded by a single-layered endodermis, and these are separated by several layers of parenchymatous cells (Fig. 3I). These paranchymatous bands are later lignified and distinguished from xylem by their larger size. A transfusion tissue composed of transfusion tracheids and parenchyma was observed in both lateral sides of the vascular bundles.

\section{Abies koreana and Abies nephrolepis}

Both these species belong to subsection Medianae of section Balsamea. Both species have almost similar tissue 


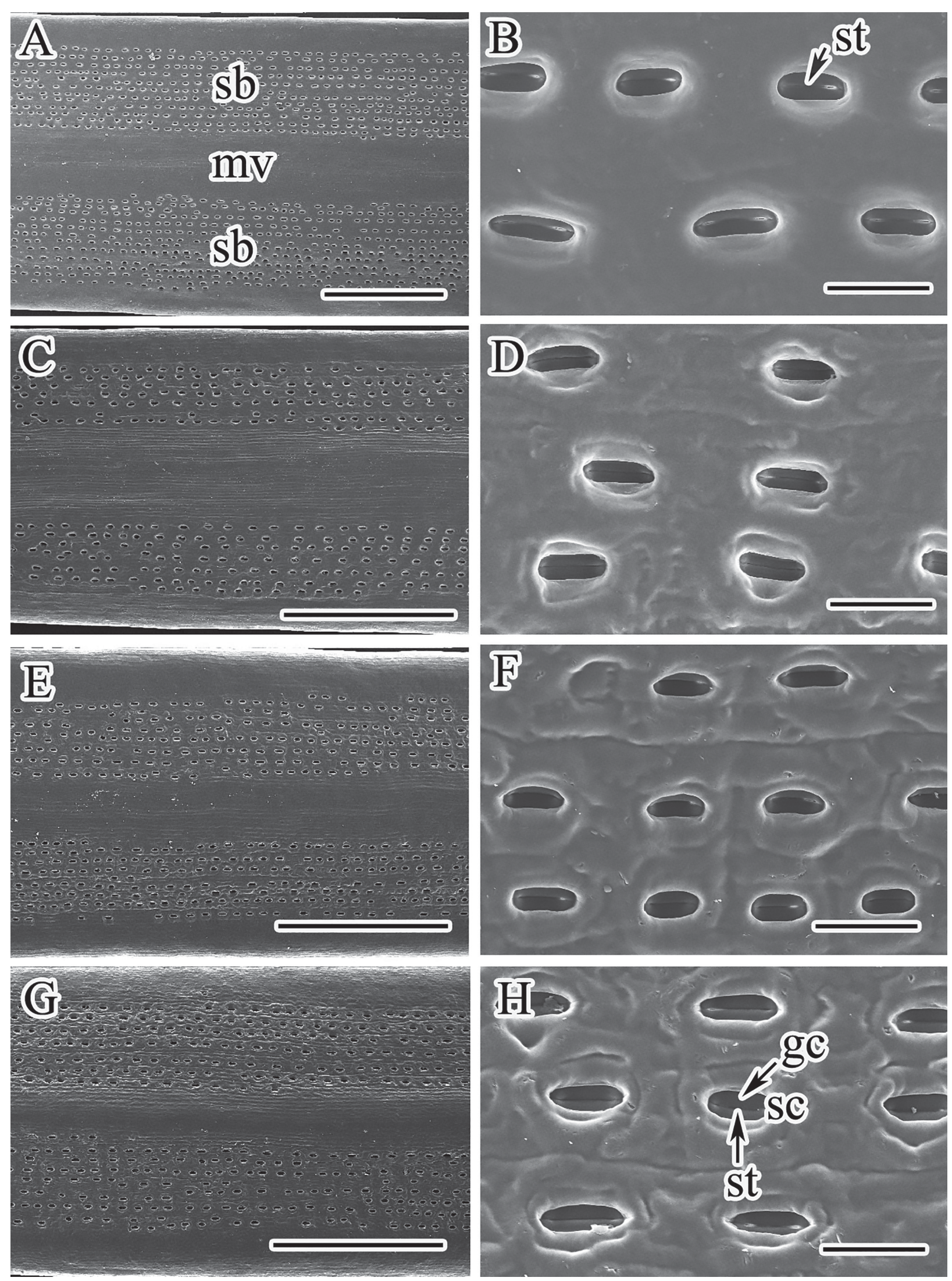

Figure 1. SEM micrograph of abaxial faces from Abies species. A, B A. firma. A Stomatal band. B Stomata magnified. C, D A. holophylla. C Stomatal band. D Stomata magnified. E, F A. koreana. E Stomatal band. F Stomata magnified. G, H A. nephrolepis. G Stomatal band. H Stomata magnified. Abbreviations: gc, guard cell; mv, mid vein; sb, stomatal band; sc subsidiary cells; st, stomata. Scale bars: A, C, E, G = $1 \mathrm{~mm}$; B, D, F, H = $50 \mu \mathrm{m}$. 

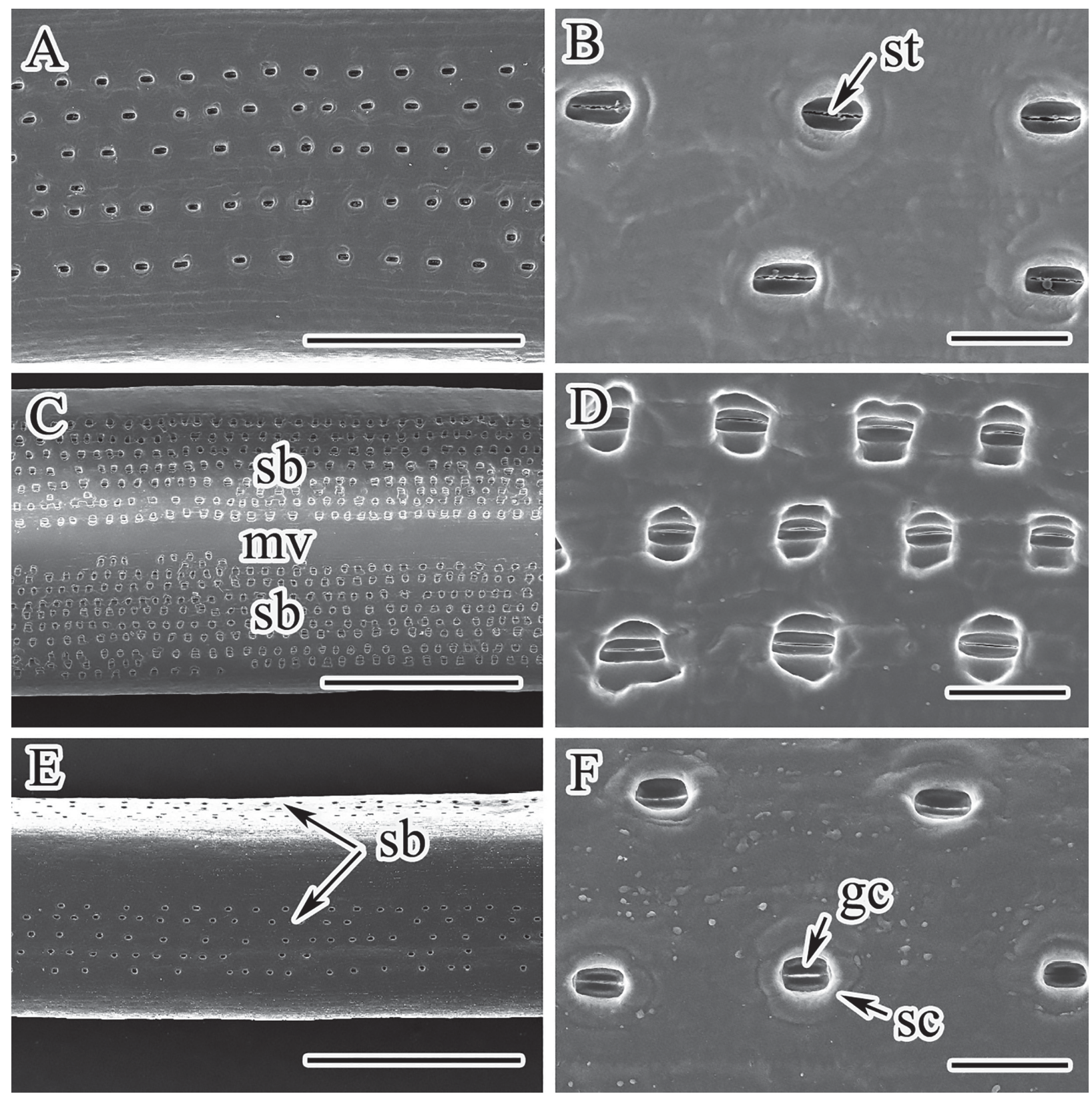

Figure 2. SEM micrograph of abaxial faces from Picea species. A, B P. abies. A Stomatal band. B Stomata magnified. C, D P. jezoensis. C Stomatal band. D Stomata magnified. E, F P. koraiensis. E Stomatal band. F Stomata magnified. Abbreviations: gc, guard cell; mv, mid vein; sb, stomatal band; sc subsidiary cells; st, stomata. Scale bars: $\mathrm{A}=500 \mu \mathrm{m} ; \mathrm{B}, \mathrm{D}, \mathrm{F}=50 \mu \mathrm{m} ; \mathrm{C}, \mathrm{E}=1 \mathrm{~mm}$.

types and arrangement as describe for first two species. In Abies koreana and A. nephrolepis there are only two resin ducts, located in the spongy mesophyll region (Fig. 3J-K). They differ from members of Momi by their hypodermis. Both species lack a continuous hypodermal layer, which is found only in a few places as either isolated cells or groups of four or five cells. In the mid vein region, the hypodermis appears as group of more than five cells (Fig. 3L-M). Stomata are restricted to the abaxial surface of the leaf (Fig. $3 \mathrm{~N}$ ). Two vascular bundles separated by layers of parenchyma cells are embedded in a single layered endodermis (Fig. 3O-P).

\section{Picea abies, Picea jezoensis, and Picea koraiensis}

In cross section, leaves of Picea abies and P. koraiensis are rectangular in shape whereas leaves of $P$. jezoensis are flattened and bifacial (Fig. 4A-E) but tissue types and their arrangement are similar in all species. The epidermis is unstratified and comprises lignified and elongated or oval-shaped cells. The stomata are highly sunken and present on both sides of $P$. abies and P. koraiensis leaves (Fig. 4A, C, F-G) and only on the adaxial surface of $P$. jezoensis (Fig. 4D-E) leaf. The hypodermis is well developed in the 

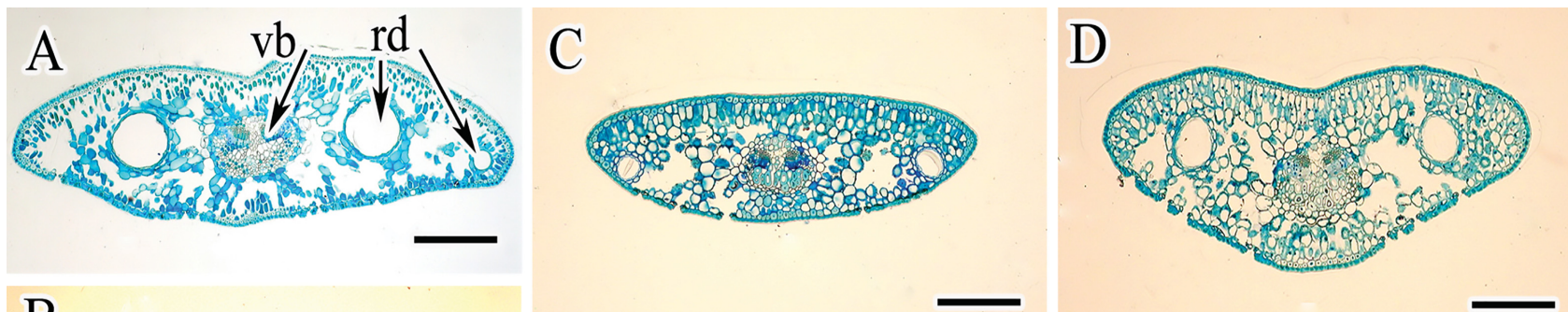

$\mathrm{B}$
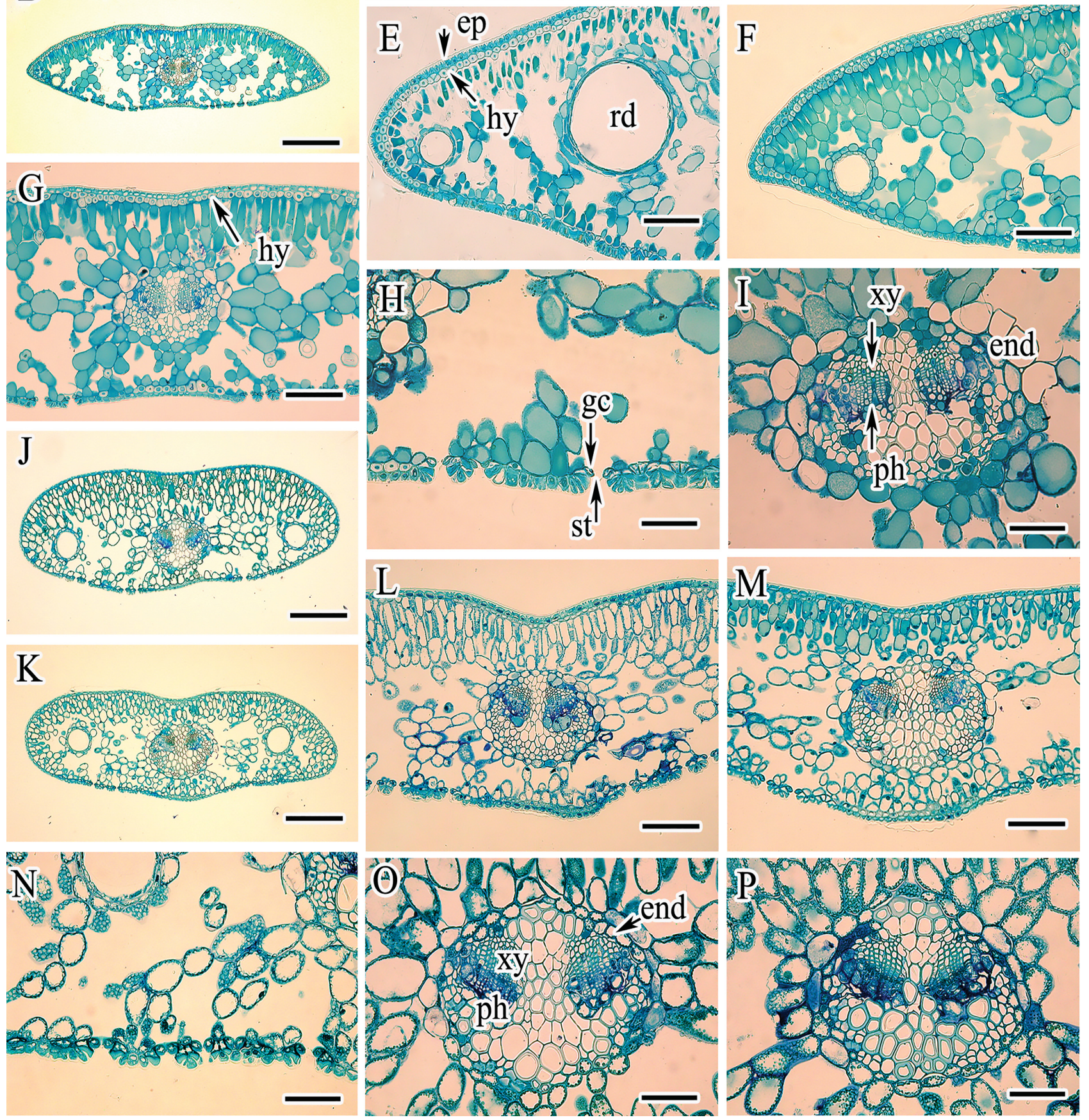

Figure 3. Cross section (CS) of Abies species. A, B A. firma. C, D A. holophylla. E, F Resin ducts of A. firma. G Mid-vein portion of A. firma. H Abaxial epidermis and stomata of A. firma. I Vascular bundle of A. firma leaf. J A. koreana leaf. K A. nephrolepis. L Portion through mid-vein of A. koreana. M Mid-vein Portion of A. nephrolepis. $\mathbf{N}$ Abaxial epidermis and stomata of A. koreana. $\mathbf{O}$ Vascular bundle of A. koreana. $\mathbf{P}$ Vascular bundle of A. nephrolepis. Abbreviations: ep, epidermis;

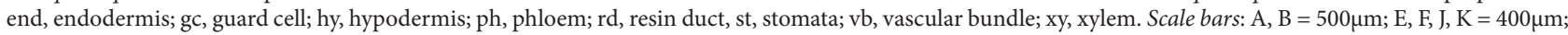
$\mathrm{G}, \mathrm{L}, \mathrm{M}=200 \mu \mathrm{m} ; \mathrm{C}, \mathrm{D}, \mathrm{H}, \mathrm{I}, \mathrm{N}, \mathrm{O}, \mathrm{P}=100 \mu \mathrm{m}$. 
three species and generally composed of a single-layer of lignified cells (Fig. 4A-B, E-H). The mesophyll is composed of elongated to polygon-shaped parenchyma cells with the palisade mesophyll poorly distinguished in the P. abies and $P$. koraiensis leaves and well developed in the adaxial surface of the P. jezoensis (Fig. 4A-E) leaf. The mesophyll cell walls have numerous infoldings projected into the cells with mesophyll of Picea species (Fig. 4F, J-K). In P. koraiensis there are one or two resin ducts are usually attached to the epidermis (Fig. 4B-C) and in P. jezoensis there are two resin ducts attached to abaxial epidermis (Fig. 4D-E, H). In all three species the vascular bundle is single or poorly divided in two by a layer of parenchyma cells and surrounded by the well-defined parenchymatous endodermis (Fig. 4J-L). A number of parenchyma cells inside the endodermis become lignified and are distinguished from the xylem cells by their larger size (Fig. 4J-L).

\section{Discussion}

Abies and Picea belong to two different main clades of Pinaceae, one comprising Cathaya, Picea, Pinus, Larix and Pseudotsuga and the other comprising Abies, Cedrus, Keteleeria, Nothotsuga, Pseudolarix and Tsuga. However,
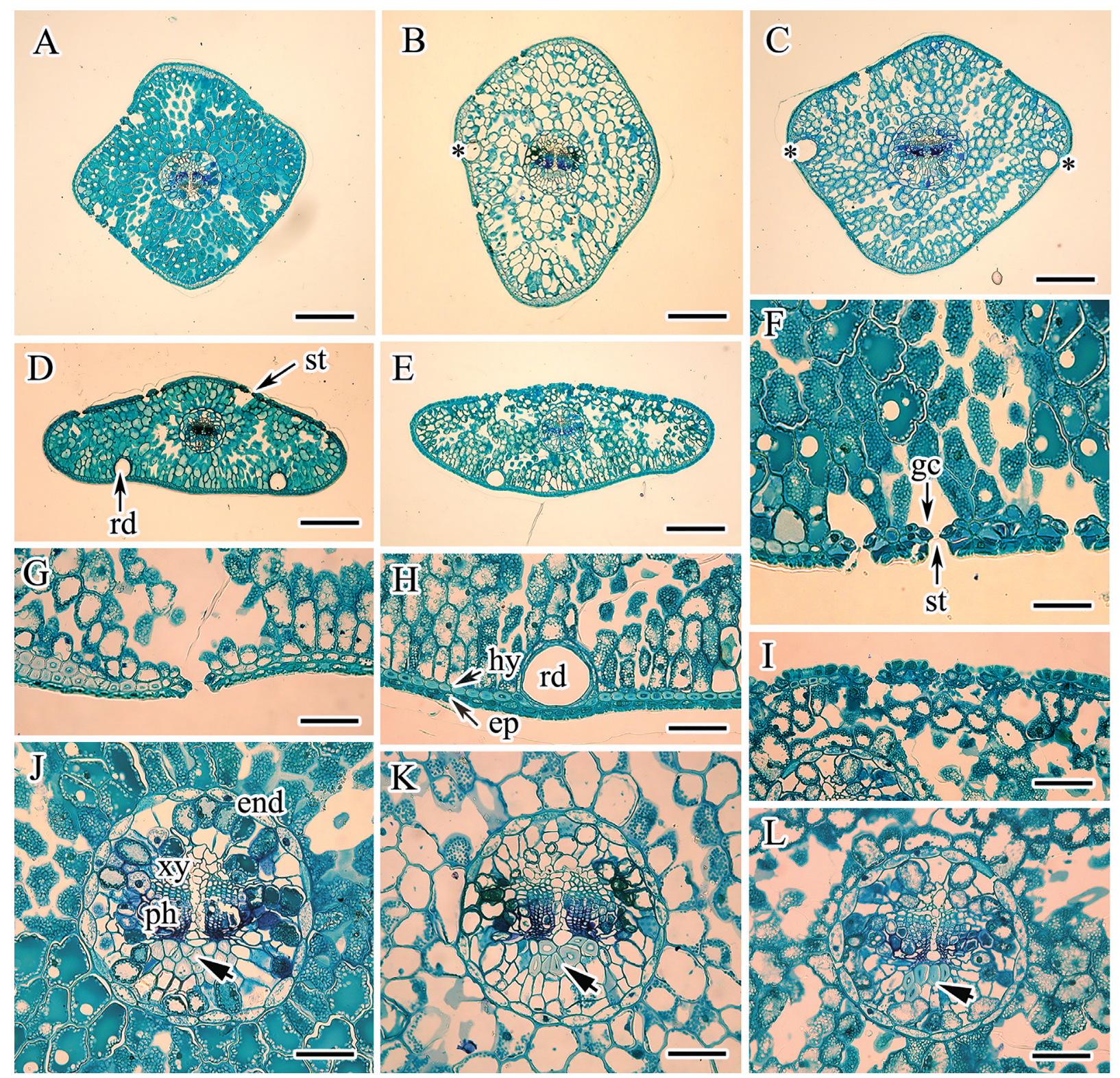

Figure 4. Cross section (CS) of Picea species. A P. abies leaf. B, C P. koraiensis with one and two resin ducts (asterisk). D, E $P$. jezoensis leaf. F Adaxial epidermis and stomata of $P$. abies. G Epidermis and stomata of $P$. koraiensis. $\mathbf{H}$ Abaxial epidermis and resin duct of $P$. jezoensis. I Adaxial epidermis and stomata of $P$. jezoensis. $\mathbf{J}$ Vascular bundle of $P$. abies. K Vascular bundle of $P$. koraiensis. L Vascular bundle of $P$. jezoensis. Abbreviations: ep, epidermis; end, endodermis; gc, guard cell; hy, hypodermis; ph, phloem; rd, resin duct; st, stomata; xy, xylem. Scale bars: A, D, E, I, J = $300 \mu \mathrm{m}$; B, C, F, G, H, K, L = $75 \mu$ m. 
based on some morphological features a few earlier studies (Pilger 1926; Melchior \& Werdermann 1954) placed Abies and Picea in the same subfamily, Abietoideae. Morphologically, these two genera exhibit similar leaf arrangement, an absence of short shoots, and similar form of the petiole pulvinus. Nevertheless, the grouping of the taxa based on these characters alone is very much artificial and this classification scheme for the Pinaceae was later rejected. By studying leaf anatomy and stomata we can see that these two genera only resemble in leaf surface and stomata features.

Within genus Abies, the species of sections Momi and Balsamea were distinguished by the nature of the hypodermal layer and the position of resin ducts. Abies firma and A. holophylla both have a continuous single-layered hypodermis whereas A. koreana and A. nephrolepis lack a continuous hypodermis, having instead isolated cells or groups of four or five lignified cells in the hypodermal region. However, this feature is not efficiently distributed in the Abies species. Bercu et al. (2010) found a continuous hypodermis in A. alba and discrete hypodermis in A. nordmanniana, and both species belong to the same section. From this it is clear that the formation of lignified hypodermis is not a significant character to distinguish section level, although it could reasonably be useful for species level. These kind of lignified cells have a protective function and thus formation of such cells might also depend on the environment condition as altitude and $\mathrm{CO}_{2}$ concentration which have a significant effect on the thickness of hypodermis in some Pinus species (Lin et al. 2001; Tiwari et al. 2013).

Both species of section Momi collected from Japan have two marginal resin ducts, and Korean samples of A. firma have two marginal and two medial resin ducts and those of A. holophylla have two medial resin ducts. On the other hand, both Balsamea species included in this study, A. koreana and A. nephrolepis, had two medial resin ducts. Eo \& Hyun (2013) described a similar position to this study for resin ducts in A. nephrolepis but found both marginal and medial ducts for $A$. koreana. They also presumed that the movement of resin ducts from the marginal to the medial position is latitude-dependent, with samples of lower latitude having marginal ducts and samples of higher latitude having medial ducts. Surprisingly enough, in this study, A. koreana, collected from three different locations including Mt. Hala of Jeju Island, had no marginal resin ducts. Bercu et al. (2010) described only marginal resin ducts in two species A. alba and A. nordmanniana of section Abies.

As already stated, the infrageneric classification of the genus remains quite controversial (Liu 1982; Schmidt 1989; Farjon 1990; 2001; Fu et al. 1999), and use of morphology alone is not a reliable guide to relationships within Picea (Ran et al. 2006; Ledig et al. 2004). Results from this study were no exception, with no significant differences observed in tissue type or arrangement in three species, except the flattened shape of P. jezoensis. P. abies and P. koraiensis resembled each other in many details, including shape and distribution of stomata, except the number and position of resin ducts. The number and position of resin ducts are also an extremely flexible character in species, as seen for A. firma in this study and for many Pinus species (Sheue et al. 2003; Tiwari et al. 2013). Furthermore, needle anatomy of North American species revealed continuous and discontinuous types of resin duct in Picea (Weng \& Jackson 2000). In this study, we did not observe the Picea needle in such a way; however, it is worthwhile mentioning that $P$. abies and $P$. koraiensis might represent the discontinuous-ducts group because different sections exhibited variation in the number of resin ducts. On the other hand, all the sections of $P$. jezoensis had two resin ducts in the same position, and so might represent the continuous-ducts group.

Stomata were distributed on the adaxial surface of $P$. jezoensis leaves, which seems unusual for a flat bifacial leaf. Identical leaf form, stomatal distribution, and equal number and position of resin ducts have been observed in section Omorika (Marco 1939). Picea jezoensis also differs from $P$. abies and $P$. koraiensis by virtue of its flexible and loosely imbricate seed scale compared to the rigid and closely imbricate seed scale in the latter two species. More importantly, in molecular phylogeny of the genus, $P$. abies and P. koraiensis were nested in the same clade and $P$. jezoensis was placed in a separate clade (Ran et al. 2006).

The common leaf anatomical features in Abies and Picea include sunken stomata, lignified single-layered epidermis with lignified hypodermis, mesophyll comprising parenchyma cells full of plastids, presence of resin ducts, and well-developed endodermis encircling either one or two fibrovascular bundles. There are two fibrovascular bundles in Abies surrounded by common endodermis and separated by a band of parenchyma tissue which is later lignified. However, in Picea the single vascular bundle is weakly divided by one or two layers of parenchyma half way through the bundle. The parenchyma bands in the middle of the vascular bundle are evidence that in an earlier evolutionary period there might have been two bundles (Marco 1939). Lacassagne (1934) stated that in the cortex (sterigmata) the bundles of the leaf trace are distinct but in the leaves they are fused. Weng \& Jackson (2000), however, showed only one vascular bundle in North American spruces.

In conclusion, leaf anatomy of both genera clearly displays the typical coniferous and xerophytic features. Some of the anatomical features, such as shape in cross section, arrangement of hypodermis, position, nature and number of resin ducts, and distribution of stomata might be key features for distinguishing species. In Abies, the species of the two sections are quite easily distinguished by the nature of the hypodermis and the position of resin ducts. However, we only considered two species from each section, and study of more species from both sections will help to validate this result. In Picea, leaf anatomical features are quietly in support of molecular data. As a result, even with geographical disjunction, $P$. koraiensis is more closely related to $P$. abies 
than $P$. jezoensis. We believe that anatomical data are useful for the systematic study of conifers and this study have provided potential output for systematic and phylogenetic studies of Abies and Picea. Similar research on other species will help to elucidate phylogenetic relationships both between species in each genus and among genera.

\section{Acknowledgements}

This study was supported by a grant from the Korea National Arboretum, funded by the Korea Forest Service of the Republic of Korea.

\section{References}

Bercu R, Broasca L, Popoviciu R. 2010. Comparative anatomical study of some gymnospermae species leaves. Botanica Serbica 34: 21-28.

Eo JK, Hyun JO. 2013. Comparative anatomy of the needles of Abies koreana and its related species. Turkish Journal of Botany 37: 553-560.

Farjon A. 1990. Pinaceae: Drawings and Descriptions of the Genera Abies, Cedrus, Pseudolarix, Keteleeria, Nothotsuga, Tsuga, Cathaya, Pseudotsuga, Larix and Picea. Koeltz Scientific Books, Konigstein, Germany.

Farjon A. 2001. World Checklist and Bibliography of Conifers. 2nd. ed. Kew, Royal Botanical Garden.

Farjon A. 2010. A Handbook of the World's Conifers. Leiden, Brill Academic Publishers.

Farjon A, Rushforth KD. 1989. A classification of Abies Miller (Pinaceae). Notes from the Royal Botanic Garden, Edinburgh 46: 59-79.

Frankis MP. 1988. Generic inter-relationships in Pinaceae. Notes from the Royal Botanic Garden, Edinburgh 45: 527-548.

Fu L, Li N, Mill RR. 1999. Picea In:Wu ZY, Raven PH. (eds.) Edited Flora of China. Vol. 4 St. Louis, Science Press, Beijing and Missouri Botanical Garden Press. p. 25-32.

Hart JA. 1987. A cladistic analysis of conifers: preliminary results. Journal of the Arnold Arboretum 68: 269-307.

Lacassagne M. 1934. Etudes morphologique, anatomique et systématique du genre Picea. Trav Lab Forestier Toulouset 2, (Etudes Dendrol. 3) Art. 1292.
Ledig FT, Hodgskiss PD, KrutovskiiKV, Neale DB, Eguiluz-Piedra T. 2004. Relationships among the spruces (Picea, Pinaceae) of southwestern North America. Systematic Botany 29: 275-292.

Lin J, Jach ME, Ceulemans R. 2001. Stomatal density and needle anatomy of Scots pine (Pinus sylvestris) are affected by elevated $\mathrm{CO}_{2}$. New Phytologist 150: 665-674.

Liu TS. 1971. A monograph of the genus Abies. Department of Forestry, College of Agriculture, National Taiwan University, Taipei.

Liu TS. 1982. A new proposal for the classification of the genus Picea. Acta Phytotaxon Geobot 33: 227-244.

Marco HF. 1939. The anatomy of spruce needle. Journal of Agriculture Research 58: 357-368.

Melchior H, Werdermann E. 1954. A Engler Syllabus der Pflanzenfamilien, 12 edn. Berlin, Gebruder Borntraeger.

Pilger R. 1926. Coniferae. In: Engler A, Prantl K. (eds.) Die naturlichen Pflanzenfamilien. Leipzig, Englmann.

Price RA. 1989. The genera of Pinaceae in the Southeastern United States. Journal of the Arnold Arboretum 70: 247-305.

Ran JH, Wei XX, Wang XQ. 2006. Molecular phylogeny and biogeography of Picea (Pinaceae): Implications for phylogeographical studies using cytoplasmic haplotypes. Molecular Phylogenetic and Evolution 41: 405-419.

Rehfeldt GE. 1994. Adaptation of Picea engelmannii populations to the heterogeneous environments of the Intermountain West. Canadian Journal of Botany 72: 1197-1208.

Rushforth KD. 1987. Conifers. New York, Facts on File.

Schmidt PA. 1989. Beitrag zur Systematik und Evolution der Gattung Picea A. Dietr. Flora 182: 435-461.

Sheue CR, Yank YP, Kuo-Huang LL.2003. Altitudinal variation of resin ducts in Pinus taiwanensis Hayata (Pinaceae) needles. Botanical Bulletin of Academia Sinica 44: 305-313.

Taylor RJ, Patterson TF. 1980. Biosystematics of Mexican spruce species and populations. Taxon 29: 421-469.

Tiwari SP, Kumar P, Yadav D, Chauhan DK. 2013. Comparative morphological, epidermal, and anatomical studies of Pinus roxburghii needles at different altitudes in the North-West Indian Himalayas. Turkish Journal of Botany 37: 65-73.

Weng C, Jackson ST. 2000. Species differentiation of North American spruce (Picea) based on morphological and anatomical characteristics of needles. Canadian Journal of Botany 78: 1367-1383.

Wright JW. 1955. Species cross ability in spruce in relation to distribution and taxonomy. Forest Science 1: 319-340. 